\title{
Helical computed tomography has a role in the screening of lung cancer - The con argument
}

\author{
Warren Davidson MD FRCPC
}

$S_{\mathrm{e}}^{\mathrm{cr}}$ creening constitutes the use of laboratory tests, physical examinations or imaging modalities performed on asymptomatic patients with the intent of identifying subclinical disease (1). As a result, screening differs from clinical investigation, in which tests are ordered after disease is suspected.

A cancer screening program is a service in which everyone in a given population is (or has the opportunity to be) examined for the presence or precursor of a type of cancer. If the screening test finds that there is a likelihood of disease, a diagnostic test may be performed for confirmation (1).

The World Health Organization has established the following principles to guide the development of a screening program (2).

- The condition should pose an important health problem.

- The natural history or progression of the disease should be well understood.

- There should be a recognizable early stage of the disease.

- Treatment of the disease at an early stage should be of more benefit than if treatment is delayed.

- There must be a suitable test.

- The test should be acceptable to the population.

- There should be adequate facilities for the diagnosis and treatment of abnormalities detected.

- For diseases of insidious onset, screening should be repeated at regular intervals determined by the natural history of the disease.

- The chance of physical or psychological harm to those screened should be less than the chance of benefit.

- The costs of screening should be balanced against the benefit it provides.

There are certain principles that are not fulfilled by chest computed tomography (CT) screening. For example:

- The natural history of lung cancer is subject to debate.

- There are no studies demonstrating improved mortality in the group screened with helical chest CT. Furthermore, treatment of early stage disease may not confer a mortality benefit.

- Repeated testing has been shown to introduce bias.

- Significant morbidity and mortality may occur with resulting diagnostic procedures or treatments.

- Significant costs are incurred by chest CT screening.

Biases inherent in screening tests can affect survival measures, casting doubt on the validity of screening test effectiveness. There are three types of bias that are of interest when considering the use of helical CT in lung cancer screening - lead time bias, length time bias and overdiagnosis bias. Lead time bias makes the assessment of mortality improvements difficult. That is, early detection of cancer or other conditions associated with increased mortality creates a backward shift in the starting point for measuring survival (earlier diagnosis), which may artificially increase incidence and lengthen apparent survival. As a result of length time bias, the probability of finding a malignancy is dependent on its growth rate. Consequently, more slow-growing tumours are found in the screened group, apparently improving survival. Overdiagnosis bias occurs when cancers are found that would not have resulted in the patient's death if never diagnosed (ie, slow growing tumours). Detection of cancer in these patients increases the risks of unnecessary cancer therapy, with no potential for clinical benefit. A recent article noted that overdiagnosis is the most likely reason that previous screening studies observed a paradoxical $11 \%$ relative increase in lung cancer mortality in screened compared with unscreened patients, which may have resulted from treatment of indolent lesions (3).

In summary, biases make the observation of increased survival an inadequate basis for inferring an effect on mortality. Therefore, case survival cannot be used to assess the effect of screening on mortality. One should use prospective mortality from the disease over a determined follow-up period after randomization; something that has not yet been done in helical CT screening for lung cancer. Furthermore, one should not compare screened patients with historical, unscreened individuals. The American Medical Association Council on Scientific Affairs stated that the only way to determine the degree of benefit without bias is by comparing people offered screening with a group of truly comparable people not offered screening (1).

For lung cancer screening with helical CT, there are a number of important, but unanswered, clinical management questions on how to best proceed with screening (4).

- What is the appropriate risk stratum to screen, and how is that stratum defined?

- What are the criteria for a 'positive' scan?

- What imaging parameters yield an optimal scan while minimizing radiation exposure?

- What is the safest and most cost-effective algorithm to work up suspicious nodules?

- What is the best procedure to remove a small lung cancer?

- How often should screened subjects with normal scans be followed with subsequent scans?

- How do we most effectively communicate the risks and benefits of a screening trial to the participants volunteering for it?

Division of Respirology, University of British Columbia, Vancouver, British Columbia

Correspondence: Dr W Davidson, Division of Respirology, University of British Columbia, St Paul's Hospital, 1081 Burrard Street, Vancouver, British Columbia V6Z 1Y6.Telephone 604-328-0918, fax 604-669-7772, e-mail wdavidson@mrl.ubc.ca 
Although it has been well documented that helical CT imaging detects lung cancer at an earlier stage than conventional chest $\mathrm{x}$-rays $(5-7)$, there is no evidence that prognosis varies with the size of a lung cancer among patients with stage $1 \mathrm{~A}$ disease. Indeed, malignancies 1 to $2 \mathrm{~mm}$ in size are able to metastasize even before angiogenesis occurs (8). Patients with $5 \mathrm{~mm}$ cancers have a clinical outcome similar to those with $30 \mathrm{~mm}$ cancers $(9,10)$. In the Mayo randomized, controlled trial of chest $\mathrm{x}$-ray screening for lung cancer (Mayo Lung Project), increased rates of surgery did not confer a reduction in lung cancer mortality (11). Furthermore, helical chest CT screening has been shown to be oversensitive. In one study that identified 2244 noncalcified nodules in 1000 persons, only 25 cases of lung cancer were found (12).

Helical CT screening for lung cancer has potentially harmful effects. False-positive findings may result in increased morbidity and mortality with associated diagnostic procedures or treatments $(13,14)$. As well, there is a significant psychological impact with a positive screening result or an actual diagnosis. False-negative tests may delay diagnosis or provide the patient with a false belief of zero risk, possibly negatively affecting future lifestyle behaviours $(13,14)$. Radiation exposure is also a concern. Based on considerations by the International Commission on Radiological Protection, it can be expected that radiation exposure with an effective dose equivalent of $1 \mathrm{mSv}$ would lead to five additional malignancies in 100,000 individuals exposed (15). Low-dose helical CT uses 0.3 to $0.55 \mathrm{mSv} / \mathrm{scan}$.

Some say helical chest CT screening is cost effective. However, analysis from the Early Lung Cancer Action Program (ELCAP) study estimates program costs as high as $\$ 93,000 /$ life saved (16). Other studies have had a higher rate of false-positives, which would increase the cost per life saved. Another recent study estimated that it would cost $\$ 116,300$ to $\$ 2,300,000 /$ quality-adjusted life-year gained (17).

To date, all trials examining helical CT scanning for lung cancer screening have been observational studies enrolling

\section{REFERENCES}

1. American Medical Association. Report 7 of the Council on Scientific Affairs (A-02). AMA Endorsement of Screening Tests or Standards 2002. <http://www.ama-assn.org/ama/pub/article/2036-6495.html> (Version current at March 23, 2004)

2. Wilson JMG, Junger G. Principles and Practice of Screening for Disease. Geneva: World Health Organization, 1968.

3. Heffner JE, Silvestri G. CT screening for lung cancer: Is smaller better? Am J Respir Crit Care Med 2002;165:433-4.

4. Mulshine JL, Smith RA. Lung cancer. 2: Screening and early diagnosis of lung cancer. Thorax 2002;57:1071-8.

5. Sone S, Takashima S, Li F, et al. Mass screening for lung cancer with mobile spiral computed tomography scanner. Lancet 1998;351:1242-5

6. Sone S, Li F, Yang Z, et al. Results of three-year mass screening programme for lung cancer using mobile low-dose spiral computed tomography scanner. Br J Cancer 2001;84:25-32.

7. Henschke CI, McCauley DI, Yankelevits DF, et al. Early lung cancer action project: Overall design and findings from baseline screening. Lancet 1999:354:99-105.

8. Patz EF Jr, Black WC, Goodman PC. CT screening for lung cancer: Not ready for routine practice. Radiology 2001;221:587-91.

9. Patz EF Jr, Rossi S, Harpole DH Jr, Herndon JE, Goodman PC. Correlation of tumor size and survival in patients with stage IA non- small cell lung cancer. Chest 2000;117:1568-71.

10. Ellis JR, Gleeson FV. Lung cancer screening. Br J Radiol 2001;74:478-85.

11. Lederle FA, Niewoehner DE. Lung cancer surgery: A critical review of the evidence. Arch Intern Med 1994;154:2397-400. volunteer cohorts. Currently, there are several randomized, controlled trials that hope to answer some lingering questions. The Lung Screening Study (LSS) will randomize 50,000 high risk patients to screening CT or conventional chest radiography; the Depiscan trial (France) will randomize 21,000 people; the NELSON trial (the Netherlands) will randomize 24,000 people; and the LUCAS trial (United Kingdom) will randomize 40,000 people. Unfortunately, the results of these studies will be not be available for another five to 10 years. Until then, we should pay attention to the experts in this field. The American Cancer Society guidelines state:

"Given the high rate of positive results that occur with CT screening for lung cancer and the complexity of the algorithm for working up small nodules, there is reason to be concerned about broad dissemination of lung screening outside of experienced, multispecialty settings and prior to validation of this new technology" (18).

Furthermore, the consensus statement from the Society of Thoracic Radiology states:

"We do not recommend mass screening for lung cancer at this time, but strongly encourage appropriate subjects to participate in trials so that the true effectiveness of lung cancer screening with LDCT can be determined at the earliest possible time" (19).

In conclusion, studies of helical chest CT for lung cancer screening have been subject to fatal biases. The procedure has many potential adverse effects and has not been shown to improve mortality. In fact, unnecessary investigations and procedures resulting from this screening protocol would expose patients to needless risks. As well, the potential financial costs of such a screening program would be enormous. Until the many questions concerning optimal clinical management are answered, screening for lung cancer with helical chest CT should not be used.

12. Swensen SJ, Jett JR, Sloan JA, et al. Screening for lung cancer with low-dose spiral computed tomography. Am J Respir Crit Care Med 2002;165:508-13.

13. Concato J. What is a screening test? Misclassification bias in observational studies of screening for cancer. J Gen Intern Med 1997;12:607-12.

14. Flood AB, Wennberg JE, Nease RF Jr, Fowler FJ Jr, Ding J, Hynes LM. The importance of patient preference in the decision to screen for prostate cancer. J Gen Intern Med 1996;11:342-9.

15. Diederich S, Lenzen H. Radiation exposure associated with imaging of the chest: Comparison of different radiographic and computed tomography techniques. Cancer 2000;89(Suppl 11):2457-60.

16. Marshall D, Simpson KN, Earle CC, Chu CW. Economic decision analysis model of screening for lung cancer. Eur J Cancer 2001;37:1759-67.

17. Mahadevia PJ, Fleisher LA, Frick KD, Eng J, Goodman SN, Powe NR. Lung cancer screening with helical computed tomography in older adult smokers: A decision and cost-effectiveness analysis. JAMA 2003;289:313-22.

18. Smith RA, von Eschenbach AC, Wender R, et al. ACS Prostate Cancer Advisory Committee, ACS Colorectal Cancer Advisory Committee, ACS Endometrial Cancer Advisory Committee. American Cancer Society guidelines for the early detection of cancer: Update of early detection guidelines for prostate, colorectal, and endometrial cancers. Also: Update 2001 - Testing for early lung cancer detection. CA Cancer J Clin 2001;51:38-75.

19. Aberle DR, Gamsu G, Henschke CI, Naidich DP, Swensen SJ A consensus statement of the Society of Thoracic Radiology: Screening for lung cancer with helical computed tomography. J Thorac Imaging 2001;16:65-8. 


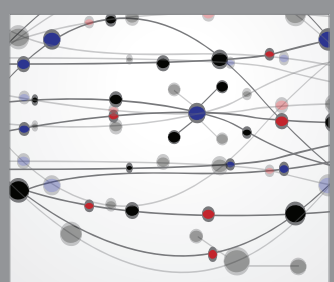

The Scientific World Journal
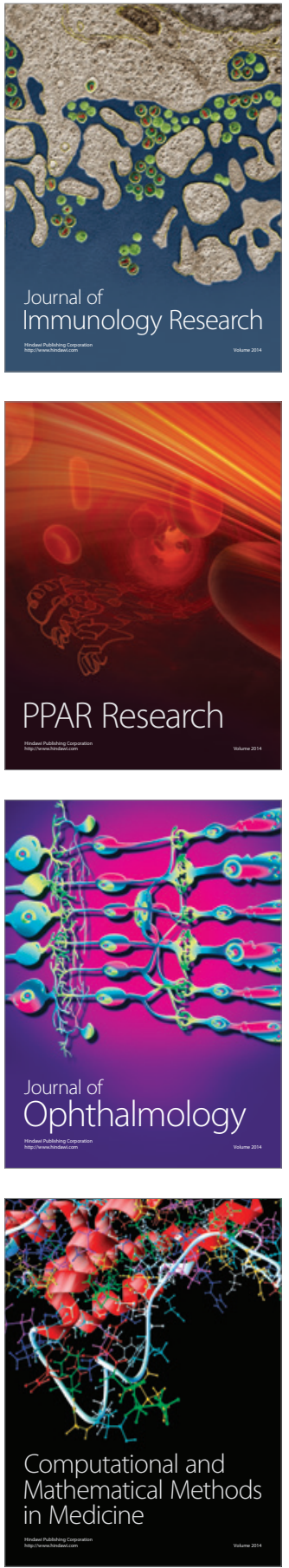

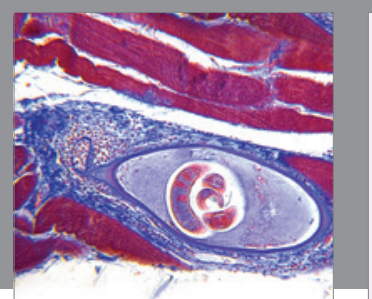

Gastroenterology Research and Practice

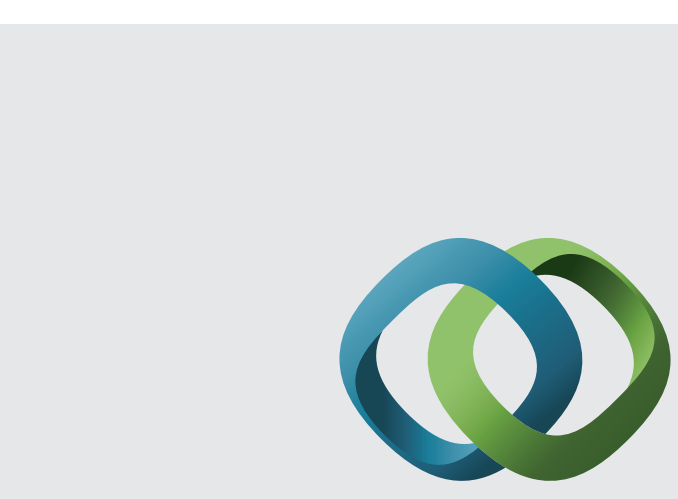

\section{Hindawi}

Submit your manuscripts at

http://www.hindawi.com
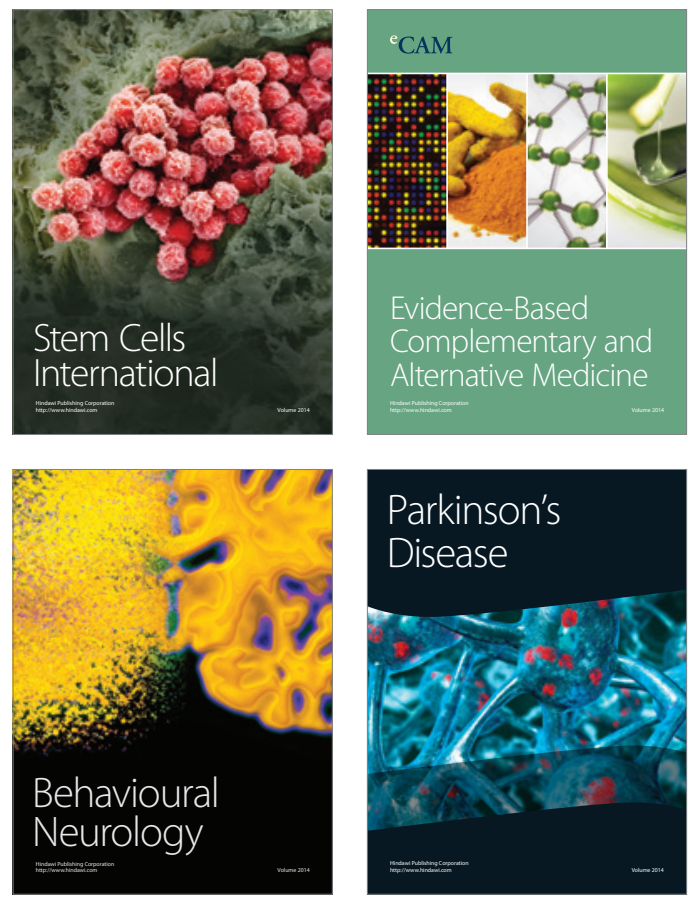
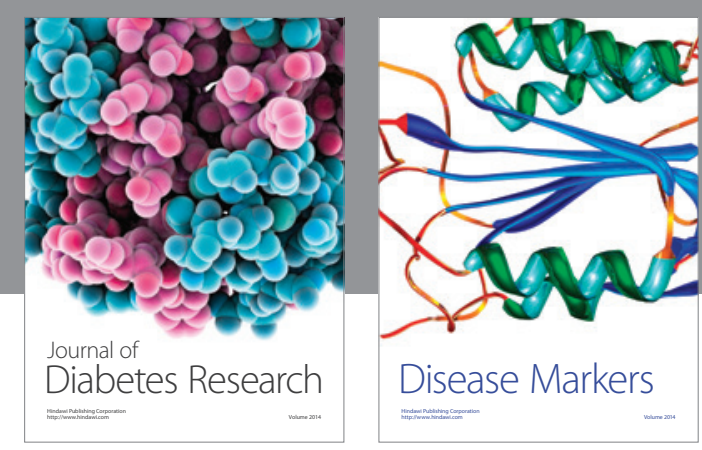

Disease Markers
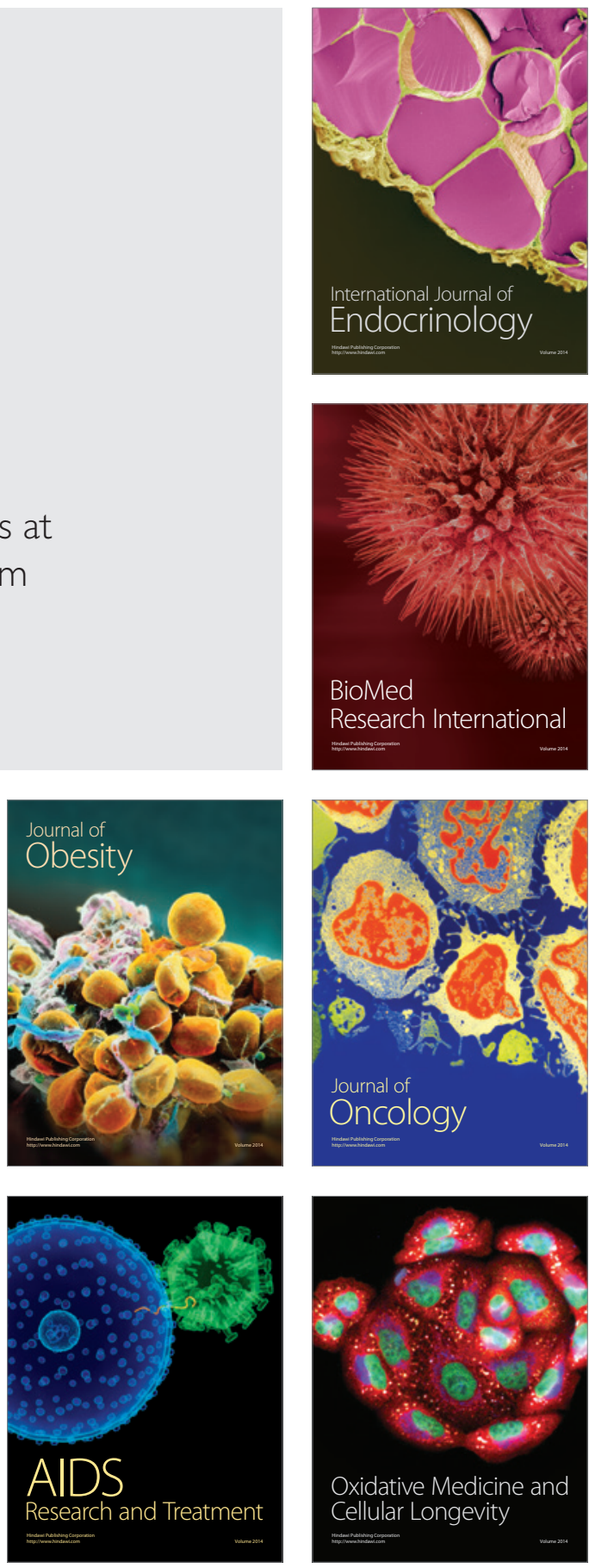